\title{
Indícios de aprendizagem significativa em alunos de uma Instituição de Educação Tecnológica na temática de Terra como um corpo cósmico
}

\author{
Nascimento, J. O. do* ${ }^{1}$, Neide, I. G. ${ }^{1,2}$, Gonzatti, S. E. M. ${ }^{1,2}$, Moret, M. A. ${ }^{1,3}$ \\ 1 Departamento de Modelagem Computacional, CIMATEC, Salvador/BA, Brasil. \\ 2 Universidade do Vale do Taquari, Lajeado/RS, Brasil. \\ 3 Universidade do Estado da Bahia, UNEB, Salvador/BA, Brasil. \\ *e-mail: jeffersonascimento@gmail.com
}

\begin{abstract}
Resumo
Na prática docente em nível superior, é comum que os discentes provenientes da educação básica apresentem conhecimentos equivocados quanto aos conteúdos físicos. Diante desta condição inicial, foi realizada a presente pesquisa, em uma turma do Programa Nacional de Integração da Educação Profissional com a Educação Básica na modalidade de Educação de Jovens e Adultos (PROEJA), em uma Instituição de Ensino de Educação Profissional. A pesquisa quali-quantitativa, realizada por meio de um estudo de caso, apresentou uma proposta de Ensino de Física por meio da modelagem e simulação computacionais, alicerçada também no referencial teórico da Teoria da Aprendizagem Significativa de David Ausubel. O objetivo do presente artigo é apresentar alguns dos indícios desta referida aprendizagem, verificados ao fim da pesquisa realizada, na temática de Terra como um corpo cósmico. Por todas as observações realizadas durante o processo investigativo, seja pela análise e transcrição das respostas dos discentes, pelas diversas interações realizadas entre eles durante a intervenção psicopedagógica e as entrevistas realizadas com eles, podemos inferir que os objetivos foram alcançados.
\end{abstract}

Palavras-chave: Ensino de Física, Teoria da aprendizagem significativa, Terra como um corpo cósmico, PROEJA.

\begin{abstract}
Neste espaço colocar o texto correspondente em inglês. Este item é obrigatório. In teaching practice at higher level, it is common for students from basic education to present mistaken knowledge regarding physical content. In view of this initial condition, this research was carried out in a class of the National Program for the Integration of Professional Education with Basic Education in the modality of Youth and Adult Education (PROEJA), in a Professional Education Teaching Institution. The quali-quantitative research, carried out through a case study, presented a proposal for Teaching Physics through computational modeling and simulation, based also on the theoretical framework of the Ausubel Theory of Meaningful Learning. The purpose of this article is to present some of the evidence of this learning, verified at the end of the research carried out, on the theme of Earth as a cosmic body. From all the observations made during the investigative process, whether through the analysis and transcription of the students' responses, the various interactions between them during the psychopedagogical intervention and the interviews conducted with them, we can infer that the objectives were achieved.
\end{abstract}

Keywords: Physics teaching, Theory of meaningful learning, Earth as a cosmic body, PROEJA. 


\section{Introdução}

A Educação de Jovens e Adultos (EJA) foi pensada primordialmente como formação inicial ou continuada para pessoas que já se encontram na fase adulta, tendo como foco a construção de um sujeito atuante e crítico no meio social, preparado para interagir com um mundo em constante transformação [1]. Conforme Freire [2] a ideia era de alfabetizar ou trabalhar a formação continuada a partir do próprio aluno, por meio das suas condições de vida e interações sociais, tornando-o um ser preparado para atuar ativamente nesta sociedade. Contudo, o que realmente acontece são pessoas voltando aos seus estudos em busca de um certificado para poder disputar uma vaga no mercado de trabalho [1].

Assim como na EJA, o aluno ao optar pelo PROEJA, não tem garantias de que ocorrerá a sua inserção no mundo do trabalho, na área de seu curso técnico, mas esta realidade não pode ser um norteador para impossibilitá-lo do acesso ao ensino médio integrado ao técnico [3]. Diferentemente do ensino médio regular, o PROEJA é formado por alunos diferenciados, que normalmente estão há certo tempo afastados do ambiente escolar [4]. Existem especificidades que devem ser pensadas na prática pedagógica docente, relativas a esta modalidade de ensino [4]. Ao retomarem os estudos, fazendo a opção por cursar o ensino médio integrado ao ensino técnico, deve-se ter um olhar especial em relação às práticas desenvolvidas e aos conteúdos abordados, haja vista a elevada complexidade que há neste retorno às aulas.

Diante desta realidade, este artigo apresenta uma pesquisa um excerto realizado com uma turma de PROEJA com a temática de Terra como um corpo cósmico, destacando as estações do ano. Assim como em [5], percebemos que este fenômeno corresponde a um dos conhecimentos científicos que mais se destaca em ser aprendido de forma equivocada. As estações correspondem a um fenômeno astronômico que, embora seja do cotidiano das pessoas, sua compreensão exige a integração de diferentes conceitos, entre eles, situar a Terra como corpo cósmico e desenvolver um modelo tridimensional para o sistema Sol-Terra [6]. Conforme Nardi e Carvalho [7] a causa e a caracterização das estações são tópicos que no ensino regular causam dificuldades de entendimento, o que a princípio me fez pensar na dificuldade que poderia ser abordá-las no PROEJA. Para mais detalhes da pesquisa, indicamos

\section{Metodologia}

Para realizar esta pesquisa, em uma escola de educação profissional em Belém/PA (turma de PROEJA técnico em Informática), em busca de possíveis respostas em relação ao ensino de Física por meio de ferramentas tecnológicas, alicercemo-nos na
Teoria da Aprendizagem Significativa de Ausubuel e, em pressupostos da pesquisa qualitativa [8], por meio de um estudo de caso. Toda a pesquisa ocorreu com atividades para os alunos, com a utilização dos objetos de aprendizagens do PHET, do Microsoft Excel e do software Modellus. Neste artigo, estes tópicos não discutidos. De forma coerente para os autores, pelo medida em que esta investigação envolveu uma intervenção pedagógica em um contexto real de sala de aula, onde se desenvolveram os processos de ensino e de aprendizagem, entendemos que esta perspectiva da abordagem qualitativa era a mais coerente com o tipo de estudo desenvolvido.

Assim como norteia Vergara [9], em relação aos fins de investigação, esta pesquisa foi definida como intervencionista, já que ela teve como foco principal se interpor e interferir na realidade dos alunos estudados, a fim de que ocorresse a possibilidade de modificá-la durante todo o decorrer do processo. Durante todo o processo de intervenção, os indícios de aprendizagem significativa estiveram sendo buscados/observados e, para que isto ocorresse, iniciamos a pesquisa com a realização de um pré-teste semiestruturado para verificar os conhecimentos prévios dos alunos e orientar o desenvolvimento das aulas seguintes [10].

A aplicação deste primeiro questionário ocorreu no primeiro encontro (primeira aula), antes do início das abordagens necessárias para o desenvolvimento da temática das estações do ano. Ao fim, ocorreu a realização de um pós-teste. Entre um e outro, alguns meses de pesquisa e várias atividades realizadas, que não seria necessário este pós-teste. Mas, optamos na realização dele.

\section{Discussão dos resultados}

De toda a pesquisa, escolheremos para este artigo, algumas questões do pós-teste para discussão. A primeira questão do pós-teste, inspirada em Gonzatti [15], abordou um texto adaptado de uma notícia publicada em um jornal virtual do Pará os prejuízos que as constantes quedas de mangas têm causado aos moradores de Belém/PA. A mangueira é uma árvore que existe em grande quantidade em Belém, o que faz com que a cidade seja chamada de "cidade das mangueiras". Nossa intenção foi de investigar a capacidade dos alunos de resolução, em relação aos conteúdos físicos pertences a temática de Terra como um corpo cósmico, conforme Figura 1: 


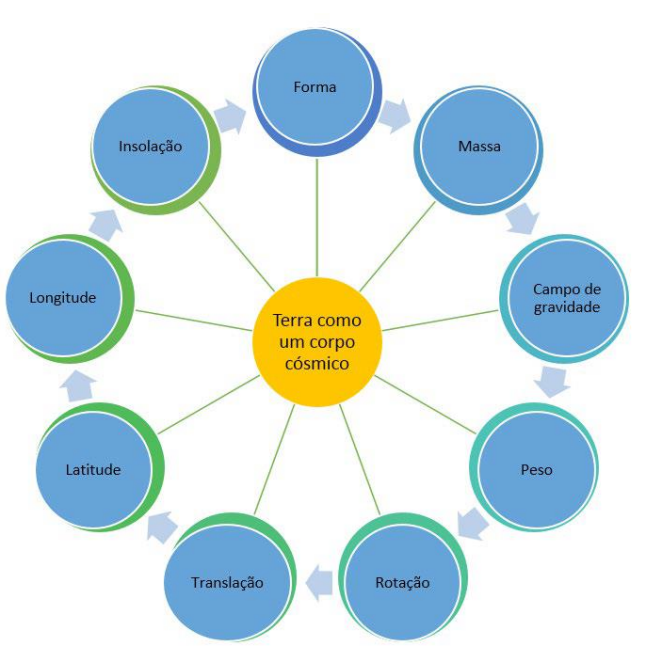

Figura 1: Terra como corpo cósmico para o estudo das estações do ano. Fonte: Nascimento [11]

A questão solicitava que fosse realizado 0 desenho da Terra, com mangueiras espalhadas ao redor do planeta e suas mangas caindo. Dos trinta alunos participantes, vinte e oito (93,33\%) apresentaram desempenho considerado coerente cientificamente, caracterizando-os como nível 3 de categorização (conforme categorização apresentada em Nascimento [11]. Um aluno apresentou resposta coerente com o nível 1 e um aluno respondeu coerentemente com o nível 2. $\mathrm{Na}$ análise realizada das respostas dos discentes, os indícios referentes a um dos três níveis, ocorreram por meio dos seus desenhos e das suas argumentações. É recorrente destacar que - nível 3 corresponde aos alunos cuja estrutura cognitiva possui conhecimentos específicos. Tais conhecimentos indicam uma construção teórica da Terra como corpo cósmico, considerando aspectos como a forma do planeta e as interações gravitacionais. Nas Figuras 2, 3 e 4, estão apresentados os desenhos realizados pelos alunos A9, A15 e A25, correspondentes aos níveis 3, 2 e 1, respectivamente:

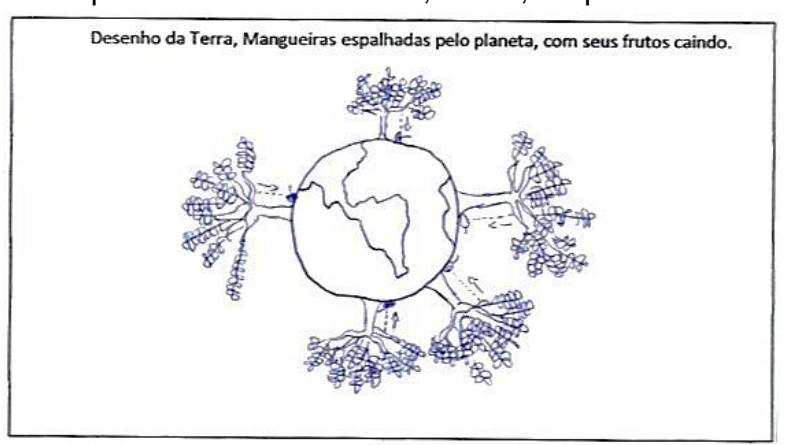

Figura 2: Resposta do aluno A9, caracterizada como nível 3

Os alunos que apresentaram suas respostas, com características do nível 3, desenharam árvores ao redor do planeta, com os frutos caindo em direção à Terra, no padrão da Figura 2. Conforme Nussbaum e Novak [12] e Baxter [13], os discentes com essas respostas possivelmente demonstraram que possuem concepções de que a Terra é esférica, fonte de um campo gravitacional, que atrai os corpos para seu centro e está situada em um espaço cósmico. Algumas argumentações dos alunos estão apoiadas nessa percepção, que foi explorada ao longo da intervenção pedagógica:

A6: As frutas em todas as partes do planeta caindo no mesmo sentido, pois há uma força gravitacional que as puxam para o centro da Terra.

A10: Devido a força de atração gravitacional do núcleo da Terra, faz com que qualquer objeto seja atraído para o centro, não importando o lado que esteja.

A18: Há Força de atração, pois os valores da massa serão sempre positivas. Desse modo será puxado para o centro da Terra.

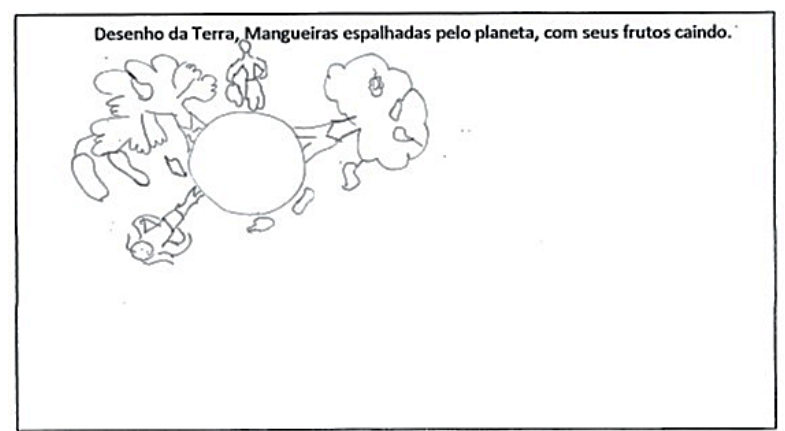

Figura 3: Resposta do aluno A15, caracterizada como nível 2

Em relação ao desenho do aluno $\mathbf{A 1 5}$ caracterizado como nível 2, durante o pré-teste semiestruturado, em análises relacionadas a temática de Terra como um corpo cósmico, o discente apresentou respostas com características do nível 1 . Possivelmente houve uma transição conceitual deste aluno, já que ele saiu de um nível de respostas egocêntricas cientificamente para um nível intermediário (nível 2) no pós-teste. O discente não explicou seu desenho na questão.

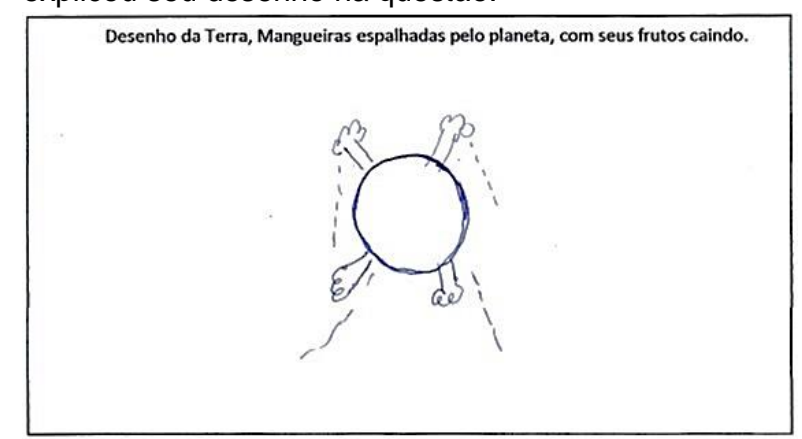

Figura 4: Resposta do aluno A25, caracterizada como nível 1

O aluno A25 apresentou resposta com características relacionadas ao nível 1, padrão já demonstrado pelo discente no pré-teste semiestruturado (não abordado nesta pesquisa). Assim como ocorreu para o aluno A15, este aluno demonstrou conhecer o formato da Terra, mas não aplicou de maneira totalmente coerente a noção da Terra como fonte de campo gravitacional. Isso foi perceptível no seu desenho: apesar das mangueiras estarem de pé em relação à superfície da Terra, em cada ponto do desenho, as frutas caem para o espaço. Essas características, conforme Nussbaum e Novak [13] 
podem indicar que as concepções de direção e sentido associadas as quedas dos corpos não estão relacionadas à Terra e ao seu centro e sim ao espaço cósmico. Conforme os autores, o desenho do aluno A25, possivelmente demonstra um desconhecimento das características da interação da Terra como corpo cósmico.

A segunda questão, inspirada em Gonzatti [14] e Nascimento, Neide e Borragini [15], solicitava que fosse feito um desenho que explicasse a ocorrência das estações do ano e, se necessário, ele poderia ser complementado com explicações escritas. Como resposta cientificamente coerente (nível 3), poderia ser feito um desenho que explicitasse a Terra com seu eixo imaginário inclinado, orbitando ao redor do Sol, por meio de uma trajetória elíptica de excentricidade baixa, sendo o desenho semelhante a uma circunferência. $O$ movimento de rotação e a força gravitacional mútua entre Terra e Sol, também poderiam ser representados no desenho. Como possibilidade do nível 3 de categorização, considerei também o desenho que representasse a Terra e o seu eixo imaginário inclinado. Dos trinta alunos participantes que responderam a questão, vinte e cinco (83,33\%) apresentaram desenhos e argumentações, conforme 0 nível 3 (Figura 5).

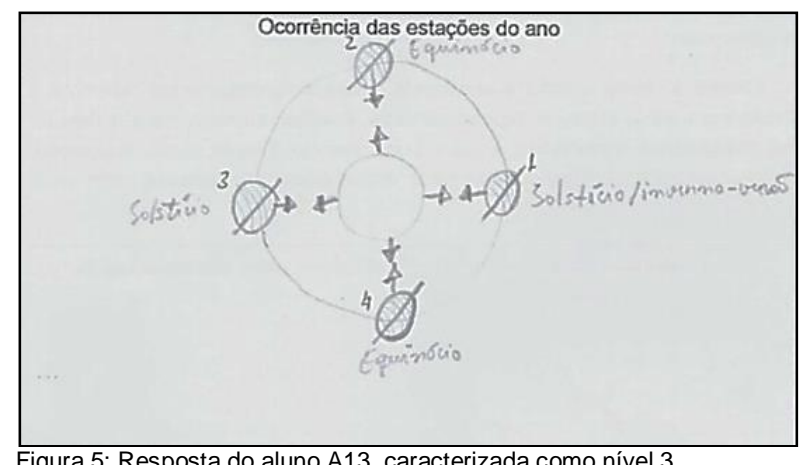

Figura 5: Resposta do aluno A13, caracterizada como nível 3

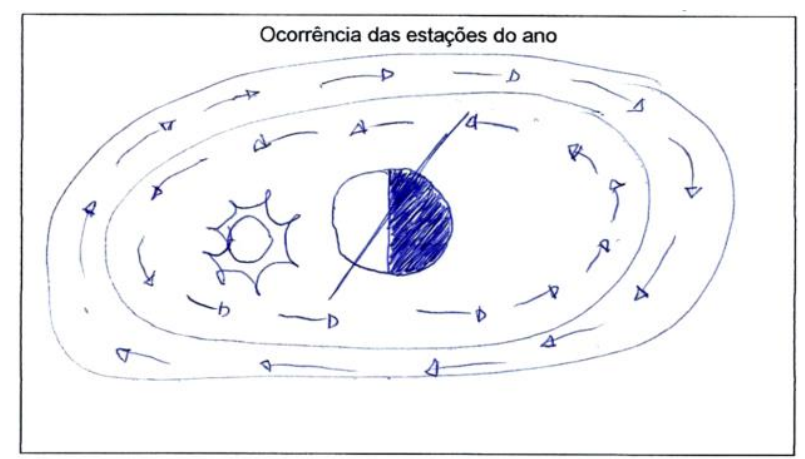

Figura 6: Resposta do aluno A26, caracterizada como Nível 2, no pósteste

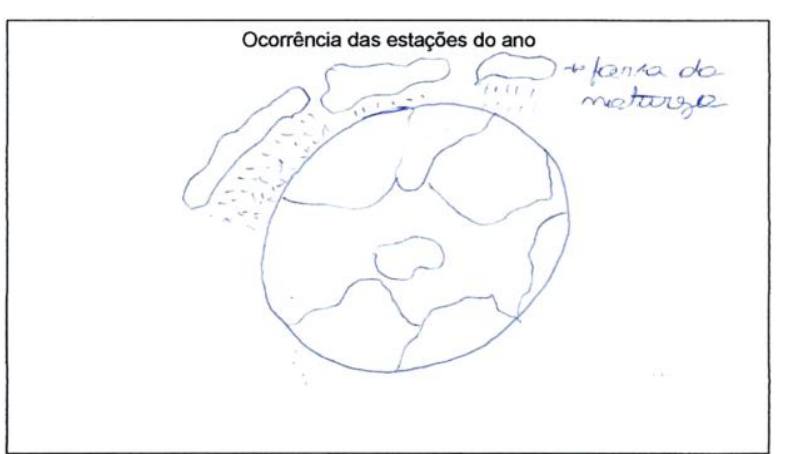

Figura 8: Resposta do aluno A9 caracterizada como nível 1, no pósteste

O desenho elaborado pelo aluno A26 apresentou características coerentes com o nível 2 de categorização, assim como sua resposta expositiva: "Inicia o verão no hemisfério sul, no norte está começando o inverno". O desenho apresentou a Terra com o seu eixo imaginário inclinado, uma separação entre regiões que corresponderiam ao período do dia (claridade) e noite (escuridão) no planeta, o Sol e duas possibilidades de sentido de movimento (não determinando a qual corpo celeste da figura pertencem os movimentos).

Mesmo o discente apresentando intuitivamente em sua resposta características como a forma da Terra, revolução, e o fenômeno dos dias e das noites (concepções necessárias para o entendimento das estações), mas ainda não apresentam-se alicerçada em um modelo coerente cientificamente. Conforme Selles e Ferreira [16] este padrão de respostas possivelmente indica um modelo conceitual do fenômeno das estações, que ainda se encontra disposto em diversos

materiais instrucionais: a Terra possui uma exagerada trajetória elíptica ao redor do Sol.

No pré-teste semiestruturado, o aluno A26 apresentou respostas para a trajetória da Terra ao redor do Sol e em relação as estações do ano, com características do nível 1 de categorização. Agora, apresentou respostas caracterizadas como nível 2, indicando uma possível transição conceitual em sua estrutura cognitiva. A resposta expositiva do aluno A9 desenvolveu-se em torno de uma explicação que envolve o ciclo da água na Terra para caracterizar as estações do ano:

" $A$ terra faz as seguintes alterações: $A$ água que está na terra, volta ao clima através da organização que ocorre constantemente, essa água passa por uma processo de acúmulo de agua na superfície da Terra após esse procedimento o acúmulo de água, ai essa água volta para a terra em forma de chuva considerando que as estações do ano que são divididas por etapa inverno, verão e primavera $e$ outono".

Mesmo com uma resposta ingênua cientificamente para esta questão e caracterizada como nível 1, ao observar o desenho realizado pelo aluno, 
constatei que o caráter esférico da Terra, a força da gravidade e o campo gravitacional estão presentes (Terra desenhada de forma esférica, com nuvens ao redor e a chuva caindo em direção ao planeta). Estes conceitos são necessários para a compreensão do fenômeno das estações do ano, remetendo-me ao pensamento que, possivelmente o aluno, cognitivamente, apresentou alguma transição conceitual, mas, ainda não conseguindo estabelecer explicações científicas referentes aos fenômenos astronômicos [17].

A sexta questão, adaptada do processo seletivo ao nível superior da Fuvest, inicialmente apresentou informações sobre 0 fenômeno da insolação e mostrou quatro figuras, em que três delas irei denominar aqui, para fins didáticos, de Figura I, Figura II e Figura III, pois representavam as estações inverno, primavera e verão, respectivamente:

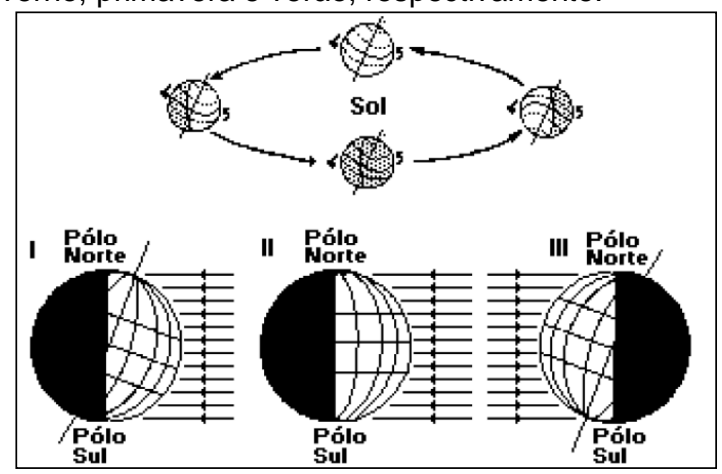

Figura 9 - Estações do ano. Fonte: Adaptado de Nascimento [???].

$\mathrm{Na}$ primeira parte da questão, os alunos deveriam identificar essas estações do ano no Hemisfério Sul do planeta. Na segunda parte, deveriam explicar as variações do período de iluminação de Belém/PA e São Paulo/SP, relacionando-as com o horário de verão. Pelas respostas apresentadas dos alunos, julguei pertinente nesta questão qualificá-las de de forma individual e agrupada, em um diagrama de Venn (Figura 10).

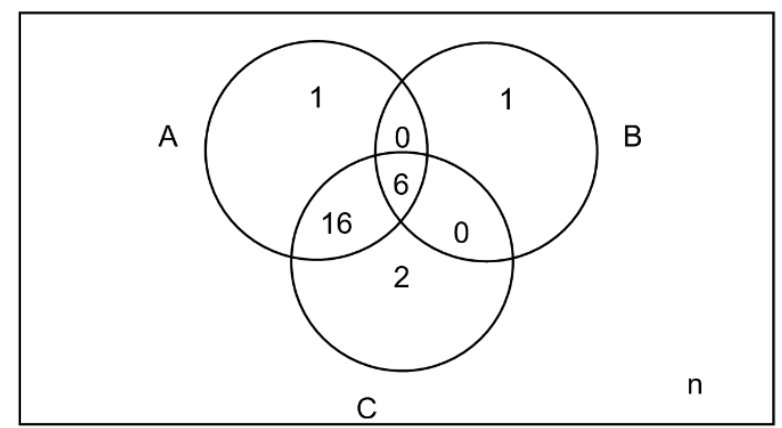

Figura 10 - Diagrama de Venn do agrupamento de respostas dos alunos. Fonte: Nascimento [11]

- $\mathrm{A} \rightarrow$ Conjunto constituídos por alunos que acertaram somente a estação representada pela Figura I (Inverno) = 1;

- $\mathrm{B} \rightarrow$ Conjunto constituídos por alunos que acertaram somente a estação representada pela Figura II (Primavera) = 1;
- C $\rightarrow$ Conjunto constituídos por alunos que acertaram somente a estação representada pela Figura III (Verão) = 2;

- $\mathrm{A} \cap \mathrm{B} \rightarrow$ Alunos que acertaram as estações representadas nas Figuras I e Figura II $=0$

- $\mathrm{A} \cap \mathrm{C} \rightarrow$ Alunos que acertaram as estações representadas nas Figuras I e Figura III $=16$

- $\mathrm{B} \cap \mathrm{C} \rightarrow$ Alunos que acertaram as estações representadas nas Figuras II e Figura III $=0$

- $\mathrm{A} \cap \mathrm{B} \cap \mathrm{C} \rightarrow$ Alunos que acertaram as três estações $=6$;

- $\mathrm{n} \rightarrow$ Alunos que não acertaram nenhuma das estações $=4$.

Conforme o diagrama de Venn (Figura 11), foi possível quantificar os dados conforme Figura 11:

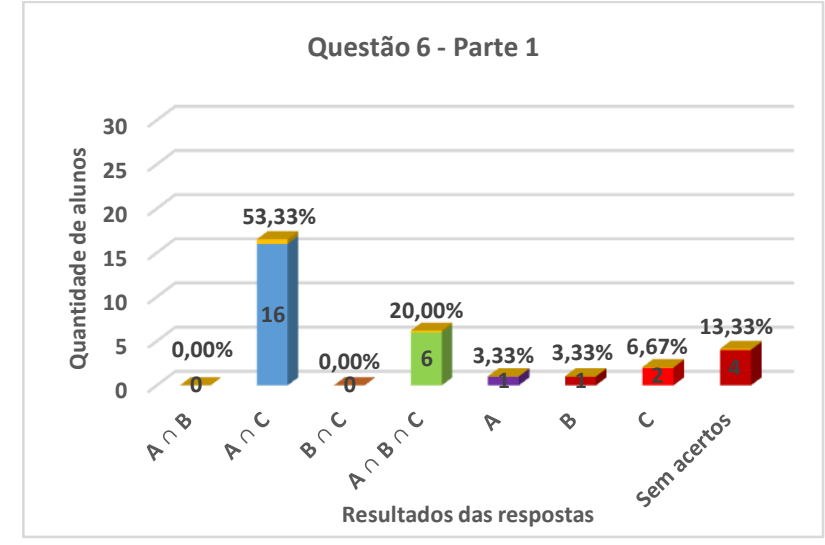

Figura 11 - Diagrama de Venn do agrupamento de respostas dos alunos. Fonte: Nascimento [11].

Para Selles e Ferreira (2004) [19] este padrão de respostas possivelmente De acordo com as informações acima construídas dos argumentos escritos pelos alunos na primeira parte da sexta questão, seis alunos (20\%) responderam de forma coerente cientificamente a primeira parte da questão, conseguindo analisar, observar e relacionar a insolação com os hemisférios da Terra nas três posições representadas. A maioria dos alunos, dezesseis $(53,33 \%)$, respondeu de forma correta as estações representadas na Figura 82, correspondentes ao inverno e verão. Quantificando os acertos individuais para cada estação do ano representada na figura, cada uma obteve um acerto. Quatro alunos, A2, A11, A14 e A29, não responderam a questão.

Para Selles e Ferreira [19], e Gonzatti [15]na região norte do Brasil, são perceptíveis apenas as estações de seca (período do ano que não chove ou chove pouco) e chuvosa (período do ano de ocorrência intensas de chuvas). De acordo com os autores essas estações são as denominas de verão e inverno nessa região e, este fato possivelmente foi refletido nas respostas dos discentes.

A maioria dos discentes, dezesseis $(53,33 \%)$, apresentaram suas respostas coerentes cientificamente para as estações verão e inverno e, mesmo a questão 
referindo-se a um Hemisfério (Sul) e não apenas a uma região específica do planeta (Norte do Brasil), a percepção e afinidade deles para essas estações se destacaram. Esta questão também indica a dificuldade que percebi que apresentaram em relação ao estudo dos solstícios e às estações primavera e outono. A segunda fase da questão seis do pós-teste, solicitava que os alunos explicassem as variações do período de iluminação para as cidades de São Paulo/SP e Belém/PA, relacionando-as com o horário de verão. É válido destacar que São Paulo dispõe de maior latitude que Belém.

Em 2014, o horário de verão iniciou na madrugada de dezoito para dezenove de outubro, finalizando em 2015, de quinze para dezesseis de fevereiro ${ }^{1}$. Mesmo que o nome seja horário de verão, este período em que se evita uma possível sobrecarga no sistema de fornecimento de energia elétrica do país nos horários de pico e, também possibilita a economia de energia ao Estado Brasileiro, é iniciado logo após o equinócio de setembro. Então, para o Hemisfério Sul do planeta Terra, corresponde a estação da primavera e não ao verão.

Novamente, conforme os três níveis de categorização, uma resposta adequada cientificamente (nível 3), corresponde a seguinte explicação: São Paulo possui maior latitude comparada a Belém, apresentando uma desigualdade entre a duração dos dias e noites, diferentemente da capital paraense. Belém se encontra próxima a região equatorial, em que não há mudanças consideráveis entre as durações dos dias e noites. Estes fatos justificam a adoção do horário de verão durante o período que equivaleria a primavera (outubro) até próximo do fim do período que corresponderia ao verão (fevereiro). A seguir apresento algumas respostas dos discentes conforme as características dos três níveis de categorização:

A4: Em São Paulo com relação ao horário de verão eles têm 1 hora a menos para sair do trabalho e mais tempo de claridade com isso aproveitam, já em belém são basicamente a mesma quantidade de horas só mudando em duas épocas do ano.

A6: Em relação a Belém as estações não são bem definidas e as variações de iluminação. Já São Paulo 'os horários tem'. Pois quando está no inverno a noite é mais prolongada e o verão é mais tempo de claridade.

A25: Horário de verão, nada a ver com Belém.

As respostas dos discentes caracterizadas como nível 1 (acima), apresentaram argumentações ingênuas cientificamente, sem alicerce em um atual modelo de ciência para a explicação do horário de verão. $\mathrm{Na}$ resposta do aluno $\mathbf{A 4}$, por exemplo, ele até cita a similaridade entre a duração dos dias e noites em Belém, mas, sem nenhuma informação mais relevante cientificamente. As argumentações dos alunos A3, A19

\footnotetext{
${ }^{1}$ Informação

disponível

em:

<http://www.horariodebrasilia.org/verao/>. Acesso em 12 de Dez. 2014.
}

e $\mathbf{A 3 0}$ apresentaram algumas características de alicerce científico, sendo categorizadas como nível 2, com as seguintes respostas:

A3: Os trópicos de câncer e de capricórnio onde o sol incide diretamente nos dias de solstícios e delimitam as regiões onde o sol incide diretamente. Na cidade de São Paulo nos solstícios [de verão] os dias são mais longos em Belém isso não acontece.

A19: O horário de verão serve apenas para uma economia de energia.

A30: O horário de verão não tem nada a ver com as mudanças de estação, tem a ver com a diminuição de energia nas cidades citadas no texto acima.

Conforme Moreira e Uhr [18] e Gonzatti [14], entre os trópicos de Câncer e Capricórnio observam-se latitudes em que os raios solares incidem diretamente nas datas dos solstícios, região onde se encontra São Paulo. A resposta do aluno $\mathbf{A} 3$ está de acordo com as autoras, mas ele cita os solstícios com características iguais ao do solstício de verão, quando se refere a um dia com longa duração. Também cita de forma coerente que em Belém não há variações expressivas na duração entre os dias e noites, mas não consegue explicar o horário de verão, em função desta desigualdade luminosa no Sudeste.

Os alunos A19 e $\mathbf{A 3 0}$ apresentam argumentações simples, mas não de forma ingênua cientificamente como as caracterizadas para o nível 1. Em relação ao nível 3, onze alunos (36,67\%) apresentaram argumentações alicerçadas em um atual modelo científico ou com respostas próximas desse modelo, apresentando um padrão verificado nas respostas dos alunos $\mathbf{A} 11$ e $\mathbf{A 1 0}$ :

A11: Os dias no sul e sudeste tem mais duração da claridade e menos tempo de duração da noite e o governo criou o horário de verão para que a população do sul e sudeste usassem menos energia elétrica porém esse horário de verão não se aplica ao Pará ou a Belém.

A10: Em Belém, devido estar mais perto a linha do equador recebe a mesma quantidade de luz o ano inteiro as noites e o dia tem a mesma durabilidade, já em SP por estar mais ao sul no período que antecede o verão entre o equinócio de setembro os dias são mais longos que a noite pois clareia mais cedo e escurece mais tarde.

$\mathrm{Na}$ resposta do aluno $\mathbf{A 1 1}$, ocorreu a afirmativa que a duração do dia é maior do que a da noite para o período que ocorre a aplicação do horário de verão. O discente justificou na sequência a ocorrência do horário de verão em função da desigualdade luminosa em São Paulo, havendo redução no consumo de energia elétrica. A afirmativa do aluno A11 está em conformidade com Uhr (2007), pois essa diferença no período de iluminação que ocorre em regiões de latitudes afastadas da região equatorial, não é perceptível para localizações próximas a ela (é o que ocorre com Belém).

Para Gonzatti [14] praticamente há doze horas de duração para a duração do dia e da noite nessas regiões próximas à equatorial. Tais argumentações também estão presentes nas respostas dos alunos A10 e A13, apresentando-se coerentes cientificamente. A seguir, percentual dos alunos em relação aos níveis de 
concepções utilizados na categorização, conforme Figura 12:

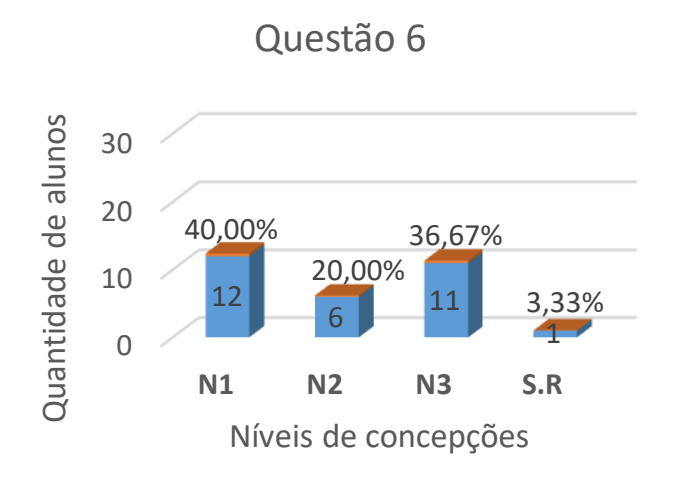

Figura 12 - Diagrama de Venn do agrupamento de respostas dos alunos. Fonte: Nascimento [11]

\section{Considerações finais}

Toda a pesquisa realizada com a turma do curso técnico em informática na modalidade PROEJA, este realizada em um questionário semiestruturado que inicialmente investigou as concepções prévias dos alunos quanto aos subsunçores necessários para as abordagens da temática de Terra como corpo cósmico. Diante destes resultados, todo o percurso metodológico pôde ser construído e adequado à realidade percebida no ambiente escola, pelos alunos.

Reconciliação integradora e diferenciação progressiva foram alguns dos fenômenos percebidos em todas as observações realizadas durante toda a pesquisa. Estes fenômenos, dentre outros, alicerçaramnos para argumentarmos que percebemos indícios de aprendizagens significativa.

Como dito anteriormente, não havia necessidade de realizarmos este teste ao fim da pesquisa. Houve material coletado suficiente já para embasar esta afirmativa. Porém, resolvemos realiza-lo e auxiliou a todas as análises e respostas que a pesquisa já havia fornecida: houve indícios de aprendizagem significa pelos alunos da turma do PROEJA.

\section{Agradecimentos}

Jefferson Nascimento agradece a oportunidade de ter realizado pós-doutoramento no departamento de modelagem computacional no CIMATEC/BA. Marcelo A. Moret agradece ao $\mathrm{CNPq}$ pelo suporte financeiro parcial oriundo de sua bolsa de Produtividade em Pesquisa (No. 305291/2018-1).

\section{Referências}

[1] ROMANZINI, Beatriz. EJA - Ensino de Jovens e Adultos e o Mercado de Trabalho. Qual Ensino? Qual
Trabalho? II Seminário de Estágio da Licenciatura em Ciências Sociais. Universidade Estadual de Londrina, $2011 . \quad$ Disponível em: <http://www.uel.br/projetos/lenpes/pages/arquivos/aBea triz\%20Artigo.pdf>. Acesso em 30 jun. 2014.

[2] FREIRE, Paulo. Pedagogia da autonomia. Saberes necessários à prática educativa. São Paulo: Paz e Terra, 1996.

[3] BRASIL. Parâmetros Curriculares Nacionais: Ciências da Natureza Matemática e suas tecnologias no ensino médio - SEMTEC/MEC - 1999. Disponível em

<http://portal.mec.gov.br/seb/arquivos/pdf/ciencian.pdf> . Acesso em: 20 de julho 2013.

[4] PEREIRA, Josué Vidal. O PROEJA no Instituto Federal de Goiás - Campus Goiânia: Um estudo sobre os fatores de acesso e permanência na escola. Dissertação de Mestrado. Unb. Brasília, 2011.

[5] Marco Antônio. Aprendizagem significativa, organizadores prévios, mapas conceituais, diagramas $\checkmark$ e unidades de ensino potencialmente

significativas. I Encontro Regional de Aprendizagem Significativa I ERAS NORTE. UEPA, Belém, 2013. Disponível

em:

<http://paginas.uepa.br/erasnorte2013/images/

sampledata/figuras/aprend_\%20signif_\%20org_prev_m apas_conc_diagr_v_e_ueps.

pdf $>$. Acesso em: 23 abr. de 2014

[6] NUSSBAUM, J. Children's Conceptions of the Earth as a Cosmic Body: a cross age study. Science Education, New York, v. 63, n. 1. p. 83-93, Jan. 1979.

[7] NARDI, R.; CARVALHO, A. M. P. Um Estudo sobre a Evolução das Noções

de Estudantes sobre Espaço, Forma e Força Gravitacional do Planeta Terra.

Investigações em Ensino de Ciências, Porto Alegre, v. 1, n. 2, p. 132-144, ago. 1996.

Disponível em:

http://core.ac.uk/download/pdf/25767424.pdf>. Disponível em: 14 set. 2015.

[8] ANDRÉ, M. E. D. A. Estudo de caso em pesquisa e avaliação educacional. Brasília: Liberlivro, 2005

[9] VERGARA, Sylvia Constant. Projetos e Relatórios de Pesquisa em Administração. 5 ed. São Paulo: Atlas, 2004.

[10] AUSUBEL, David Paul. Aquisição e retenção de conhecimento: uma perspectivacognitiva. Lisboa: Plátano Edições Técnicas, 2003.

[11] NASCIMENTO, Jefferson Oliveira do. O Ensino de Física por meio de ferramentas tecnológicas: um estudo de caso com o PROEJA. 2015. $231 \mathrm{f}$. Dissertação (Mestrado em Ensino de Ciências Exatas) - Universidade do Vale do Taquari, Lajeado, 25 set. 2015.

[12] NUSSBAUM, Joseph; NOVAK, Joseph D. An assessment of children's concepts of the earth utilizing 
structured interviews. Science Education, v. 60, n. 4, p. 535-550, 1976.

[13] BAXTER, J. Children's Understanding of Familiar Astronomical Events. International Journal of Science Education, London, v. 11, n. 5, p. 502-513, 1989. Special issue.

[14] GONZATTI, Sônia Elisa Marchi. Um Curso Introdutório à Astronomia para a Formação Inicial de Professores de Ensino Fundamental, em nível médio. Dissertação (Mestrado Profissional em Ensino de Física) - Instituto de Física, Universidade Federal do Rio Grande do Sul, Porto Alegre, 2008.

[15] NASCIMENTO, J. O. do; NEIDE, I. G. ; BORRAGINI, L. F. . Modelagem computacional com o Software Modellus: Estudando as estações do ano.. In: XV EPEF - Encontro de Pesquisa em Ensino de Física, 2014, São Sebastião-Maresias/SP. Anais do XV EPEF, 2014. v. 1. p. 1-8.

[16] SELLES, Sandra Escovedo; FERREIRA, Marcia Serra. Influências histórico-culturais nas representações sobre as estações do ano em livros didáticos de ciências. Historic-cultural influences about patterns of representantions about seasons in primary school science textbooks. Ciência \& Educação, v. 10, n. 1, p. 101-110, 2004.

[17] LANGHI, Rodolfo. Educação em Astronomia: da revisão bibliográfica sobre concepções alternativas à necessidade de uma ação nacional. 2011. Disponível em:

<https://periodicos.ufsc.br/index.php/fisica/article/view/2 175-7941.2011v28n2p373/19323>. Acesso em: $10 \mathrm{fev}$. 2014.

[18] MOREIRA, M.A. UHR, A. P. O Sistema Solar: Um programa de Astronomia para o ensino médio. Textos de Apoio ao Professor de Física - Programa de PósGraduação em Ensino de Física, Porto Alegre, v. 18, n. 6, 2007. Disponível em: $<$ http://www.if.ufrgs.br/tapf/v18n4_Uhr.pdf >. Acesso em 01 out. 2013. 